\title{
ANÁLISE DA PAISAGEM DO PRUDENSHOPPING E DO CENTRO DE PRESIDENTE PRUDENTE, SP: UMA CONTRIBUIÇÃO PARA A PROPOSTA DE INTERVENÇÃO
}

\author{
Aline Kuramoto Gonçalves ${ }^{1}$
}

Heloísa Mariz Ferreira ${ }^{2}$

Gustavo Antônio Valentim³

\section{RESUMO}

A partir da apresentação de conceitos de paisagem, espaço e sociedade de consumo, os autores tratam da perda de importância do centro da cidade no cotidiano das pessoas, com o surgimento de espaços de consumo mais modernos, como os shopping centers. Através do entendimento do centro como um local não só de consumo, mas também do encontro, onde importantes relações são estabelecidas, já que neste se encontram pessoas de diferentes segmentos sociais, o presente artigo propõe algumas intervenções culturais e no ambiente construído, a fim de tornar o centro um local mais atrativo a população para compras, lazer e recreação, sem igualar-se a outros espaços de consumo, mas através do reforço de elementos característicos.

PALAVRAS-CHAVE: sociedade de consumo; centro; shopping center.

\section{ANALYSIS OF THE PRUDENSHOPPING LANDSCAPE AND CENTER PRESIDENTE PRUDENTE, SP: A CONTRIBUTION FOR INTERVENTION PROPOSAL}

\footnotetext{
${ }^{1}$ Geógrafa, Mestranda em Agronomia, UNESP/FCA. aline587@gmail.com

2 Geógrafa, Mestranda em Geografia, UNESP/FCT. heloisamariz@gmail.com

${ }^{3}$ Geógrafo pela UNESP/FCT. gustavoantonio.valentim@gmail.com
} 


\section{Revista Nacional de}

Gerenciamento de Cidades

foi capaz de atrair grande número de citadinos, que deixam de frequentar, ou o fazem mais esporadicamente, o centro da cidade.

Neste sentido, nossa finalidade é analisar as formas da paisagem do consumo e, assim, comparar as potencialidades entre os dois espaços de consumo. Posteriormente, a partir disso, vamos propor intervenções.

\section{OBJETIVOS}

O objetivo do presente trabalho consiste em compreender a paisagem do Prudenshopping e do "calçadão" de Presidente Prudente - SP, como formas de consumo do lugar e realização de relações sociais, buscando interpretar as potencialidades paisagísticas e como isso pode ser transformado pelo poder público. Além disso, tem-se como finalidade analisar as formas da paisagem do consumo através das unidades simbólicas de reprodução da ideologia contemporânea, e assim, comparar as potencialidades entre os dois espaços de consumo, bem como buscar soluções viáveis às intervenções na paisagem do calçadão, tornando este espaço mais atrativo.

\section{METODOLOGIA}

\section{ASPECTOS HISTÓRICOS DO CENTRO DE PRESIDENTE PRUDENTE}

A formação do centro de Presidente Prudente (Figura 1) está atrelada ao quadrilátero constituído por quatro avenidas: Washington Luiz, Brasil, Manoel Goulart e Coronel José Soares Marcondes. Área próxima à estação ferroviária, logo nos primeiros anos de conformação da cidade, exibiu a presença de estabelecimentos comerciais e de serviços, que atendiam os habitantes recém chegados e os residentes no campo (ABREU, 1972). 


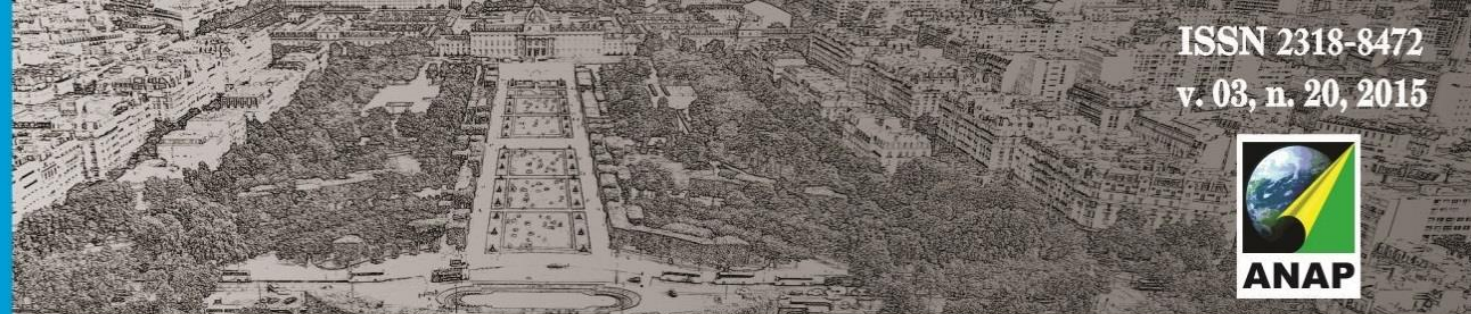

\section{Revista Nacional de}

Gerenciamento de Cidades

$\mathrm{Na}$ área central de Presidente Prudente, é possível destacar três pontos que apresentam grande circulação de pessoas, motivados pelos mais diversos interesses. São eles a Praça da Bandeira, que teve sua morfologia inicial alterada ao ser apropriada pelo comércio informal do Shopping Popular (Camelódromo); o Calçadão da Rua Tenente Nicolau Maffei, voltado ao comércio formal com lojas de diversos segmentos; e as Praças Nove de Julho e Monsenhor Sarrion, que são vistas como um ponto de encontro por parte da população.

Embora o centro da cidade tenha, a partir dos anos de 1980, exibido dinâmicas de expansão, conformando uma área bem mais extensa que aquela delimitada pelas quatro avenidas, estes pontos permanecem bastante relevantes para o conjunto da cidade.

Figura 1: Área central de Presidente Prudente.

PRESIDENTE PRUDENTE:

ÁREA CENTRAL - FEIRA AV. MANOEL GOULART

(2004)
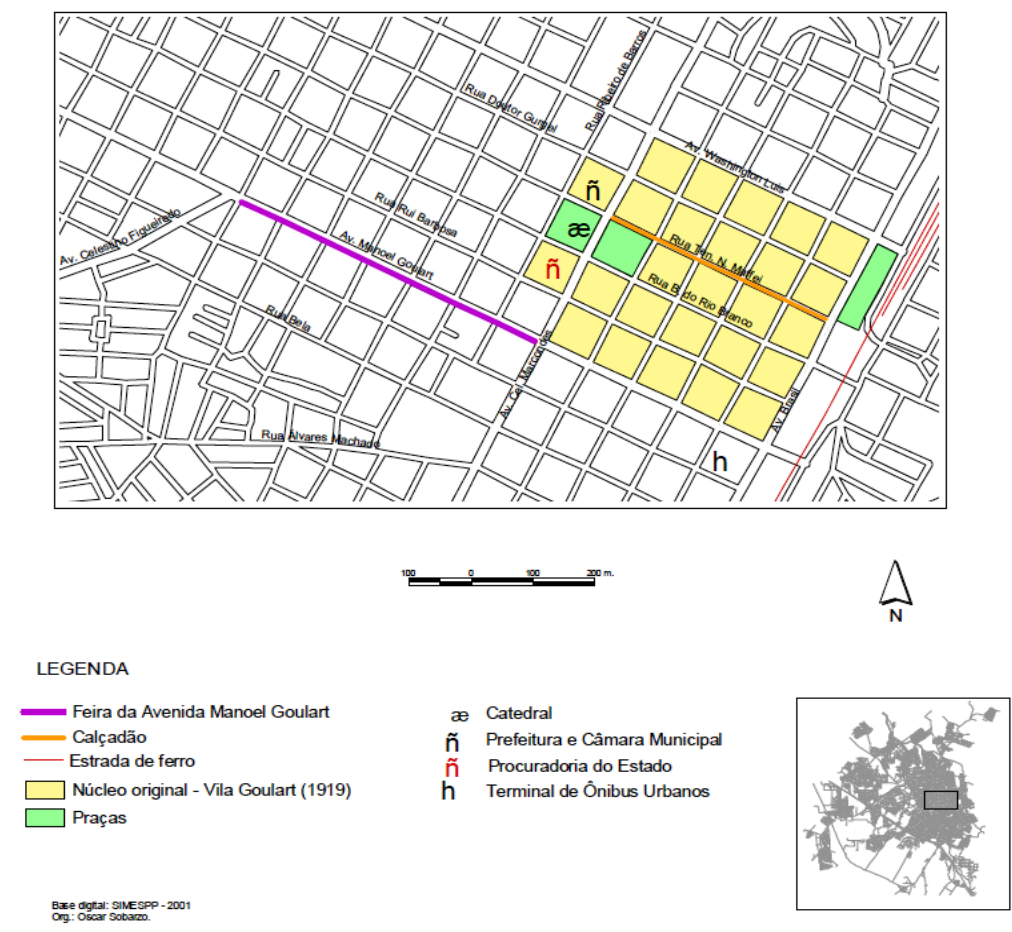

Fonte: SOBARZO, 2004, p. 169. 
De acordo com AGOSTINHO (2009):

\title{
Revista Nacional de
}

Gerenciamento de Cidades

\begin{abstract}
A noção de centro da cidade agrega diferentes conotações ao longo da história, como centros comerciais, centros religiosos, centro tradicional, centro de negócio, entre outros. Porém todas essas conotações convergem para características de um local de vida dinâmica, caracterizado pelo fluxo de pessoas e mercadorias, pontos nodais, sedes de empresas e diversidade de serviços terciários (AGOSTINHO, 2009, p. 5-6).
\end{abstract}

A Praça Nove de Julho foi inaugurada em 1933 e passou a ser um importante ponto de encontro da cidade; após alguns anos de sua inauguração foi instalada uma fonte luminosa no lugar do coreto e houve algumas mudanças no traçado. Já a Praça Monsenhor Sarrion, localizada em frente à anterior, foi inaugurada em 1942, e caracterizava-se pela presença da igreja matriz (posteriormente tornada catedral) e por um coreto.

A construção desse novo espaço acarretou a valorização do entorno, de modo que os principais prédios da cidade como Fórum, Prefeitura Municipal, entre outros, foram construídos ao redor dessas praças. Inicialmente, consistiram em imensos espaços abertos, sem vegetação, servindo apenas para a circulação de pessoas. Porém, após passarem por um processo de transformação e aquisição de equipamentos, tornaram-se mais agradáveis estética e funcionalmente, caracterizando-as como praças-jardim. Essas transformações foram de suma importância, pois se constituem como um marco fundamental da valorização de locais públicos ocorrida após esse momento, pelo poder público municipal (MANCINI, 2008).

A partir de então, segundo Mancini (2008), as praças foram vistas como lugar festivo e de lazer da população. Após as missas realizadas na igreja matriz, a praça se tornava um lugar de encontro e de conversa, além disso, se oferecia atrativos culturais que despertavam o interesse da população.

No período noturno, não eram somente as caminhadas realizadas ao redor da praça que proporcionavam o flerte e o encontro dos jovens que mantinham o 
ânimo desse lugar, havia também a interação e integração com o antigo cinema João Gomes e com os cafés e bares existentes no centro, além de um sistema de alto-falantes que transmitia recados, notícias e músicas. Esse conjunto de elementos possibilitava a prática do footing, caracterizando a maior distração da juventude na época (SOBARZO, 2004).

A partir de 1960, essas praças passaram a ser ponto de convergência das linhas de transporte coletivo do município, devido a sua localização estratégica que compreende as quatro principais avenidas já mencionadas e que proporcionam acesso a grande parte da cidade. Sendo assim, perde-se o caráter de lugar de lazer para adquirir o caráter de funcionalidade relacionada ao transporte público, tornando-se locais de passagem (MANCINI, 2008).

Essa modificação foi nítida e radical, pois produziu alterações significativas nos equipamentos e conteúdos das praças, visto que o coreto e várias árvores da Praça Monsenhor Sarrion foram retirados para que uma parte da praça fosse destinada ao estacionamento de veículos. Posteriormente, foram realizadas outras mudanças nessas praças, com derrubadas de árvores e diminuição das calçadas para criar baias para a parada de ônibus (MANCINI, 2008).

Na década de 1980 foi inaugurado o "Calçadão" de Presidente Prudente, o projeto inicial era a construção de dois calçadões paralelos, nas ruas Tenente Nicolai Maffei e Barão do Rio Branco e, por disputas políticas, foi implantando apenas na primeira rua (SOBARZO, 2004).

Buscando a revitalização do centro, no ano de 2001, a prefeitura de Presidente Prudente instalou um posto policial e retirou os camelôs da Praça Nove de Julho; também houve outras propostas de revitalização que não foram implantadas por ter ocorrido conflitos entre o público e o privado nesse episódio.

No ano de 2011, o calçadão passou por uma reforma onde foram substituídos os pisos, os bancos, a iluminação e o paisagismo, entretanto, essa reforma foi insuficiente no que se refere à atração do público, visto que não foram construídos elementos de lazer e cultura que chamem a atenção da população. 
Revista Nacional de

Gerenciamento de Cidades

Essa reforma fez parte da ideia de complementação dos investimentos no quadrilátero central da cidade, que abrangeu também a Praça Nove de Julho.

Não podemos falar que o centro de Presidente Prudente está sem vida, mas o mesmo passou pelo processo de esvaziamento e abandono como área de lazer por parcelas da população, sendo ainda muito apropriado no uso do cotidiano, para realização de tarefas no comércio, como por exemplo, pagamento de contas, atividades bancárias, entre outros. Dessa forma, o comércio e a prestação de serviços ainda proporcionam movimento e vida a esse lugar, além disso, o centro se apresenta como um referencial para manifestação popular, já que a maioria das reivindicações e protestos é realizada nesse lugar (SOBARZO, 2004).

Segundo o autor, atualmente nota-se no centro uma apropriação no sentido de passos rápidos e dos passos lentos. Por um lado, é lugar de pessoas apressadas que estão se dirigindo aos empregos, a realizar compras ou até mesmo para pagar contas, para essa parcela da população o centro é lugar de permanecer pouco tempo ou apenas lugar de passagem. Por outro, para os usuários de passos lentos, aqueles que não têm pressa, caracterizados majoritariamente pelos idosos e/ou aposentados, para os quais o centro representa um lugar de encontro e lazer, pois se aglomeram para realizar jogos de cartas na Praça Nove de Julho. Todavia, há reclamações por parte desses usuários, visto que só realizam essa atividade de lazer durante o dia e quando não está chovendo, tendo em vista que o local é perigoso à noite e não possui proteção contra a chuva. Sobre os dois tipos de apropriação do lugar, assim se refere o autor:

Em síntese, a apropriação do centro demonstra essa mistura de passos rápidos e passos lentos, de atividades comercias e de serviços, de reivindicações que indicam que esse trata de um espaço cheio de vida, que somente perde sua vitalidade à noite e nos fins de semana, quando o comércio e os serviços deixam de funcionar, mas representa, ainda, um referencial importante para grande parte da população prudentina [...] (SOBARZO,2004, p. 161).

O esvaziamento dos espaços públicos, em especial das praças centrais de Presidente Prudente, pode ser atribuído ao surgimento de novas áreas centrais, 
Revista Nacional de

Gerenciamento de Cidades

como os shopping centers, que passaram a ser lugares de recreação de uma parcela da população de maior poder aquisitivo; em segundo lugar, as novas formas de entretenimento e de lazer como o generalizado uso de televisões e de internet, que fez com que a população permaneça mais dentro de casa ou até mesmo busque novas formas de lazer fora da cidade; em terceiro lugar podemos destacar a perda de espaços públicos do pedestre para o automóvel, devido ao grande número de veículos, que dificulta a realização de caminhadas e de exercícios físicos; por último, mas não menos importante, pode-se falar do descaso do poder público em relação a manutenção, cuidado e recreação das praças, sendo que atualmente esses espaços são vistos como áreas violentas e inseguras, cujas mudanças de usos provocaram a deterioração dos conteúdos sociais e culturais.

Por outro lado, os shopping centers, sobretudo o Prudenshopping, caracterizam-se como expressões da modernidade e passaram a ser entendidos como padrão de qualidade e bom gosto. A implantação deste novo modelo de consumo e lazer na cidade incitou uma nova forma de sociabilidade, mais segmentada, que alterou a preferência do público, o qual anteriormente se direcionava ao centro tradicional com a mesma finalidade (SOBARZO, 2004).

De acordo com essa perspectiva, Sobarzo relata a diferença entre essas formas de consumo, em que:

[...] um indivíduo (o consumidor) tinha uma relação direta com o coletivo (o conjunto de outros consumidores e frequentadores do centro), circulando num espaço público (a rua) e consumindo num espaço privado (a loja). O shopping Center significa que um indivíduo consome e circula em espaços privados, rodeado de outros indivíduos cuja soma não tem capacidade de construir o público, visto que se trata de uma praça segmentada, orientada para uma parcela limitada da população ( SOBARZ̧O, 2004, p. 123).

É importante descrever alguns elementos constituintes da arquitetura do shopping center, pois esses estão intimamente ligados às representações ideológicas de uma sociedade e apresentam-se como uma sedução materializada. 
A arquitetura do shopping valoriza a noção de espetáculo, podendo ser analisada pelo campo da cenografia. Os elementos desse cenário se constituem como linguagem visual e instrumentos de persuasão, os quais influenciam de forma decisiva na construção de identidade social de cada um, de modo que, mesmo os que não frequentam se sentem "enfeitiçados" e almejam frequentá-lo (PADILHA, 2006).

Praticamente a totalidade dos aspectos visuais dos shopping centers tem como finalidade destacar a mercadoria e incentivar o consumo, isso se traduz em sua própria estrutura. Podemos destacar a iluminação artificial, a qual não permite que o consumidor perceba o passar do tempo no local, além disso, não são expostos relógios, com o mesmo objetivo. As vitrines são chamativas e iluminadas, ressaltando sempre a mercadoria; ausência de assentos e bancos para incentivar a circulação de pessoas; ambiente climatizado proporciona o bem estar da população; facilidade no acesso a serviços bancários entre outros.

\section{RESULTADOS}

\section{CONCEPÇÕES DA PAISAGEM}

Para Milton Santos (1988), a paisagem é a forma que revela relações sociais passadas e presentes entre o homem e a natureza, ou seja, é a sua materialidade, passíveis de serem abarcadas pela visão. É neste sentido que depende enormemente da percepção do indivíduo, que, posteriormente, é interpretada, tornando-se conhecimento.

A paisagem é formada por meio de processos sucessivos, mas nunca se apresenta de forma estática. No entanto, atualmente, estando a paisagem inserida no modo de produção capitalista, ela reflete o ordenamento demandado pelo mesmo, o que pode ser visto nas cidades, produzidas para atender às demandas do 


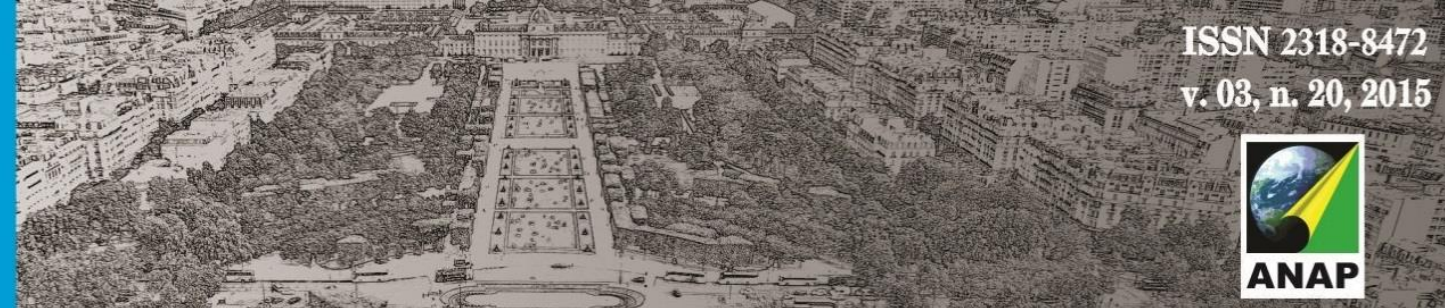

Revista Nacional de

Gerenciamento de Cidades

capital. "A cidade é essa heterogeneidade de formas, mas subordinada a um movimento global" (Carl Sauer,1988, p. 23).

Não quer dizer, entretanto, que os objetos do passado sejam suprimidos, mas, na verdade, mesclam-se com os do presente, por vezes ainda comportando a história da cidade, dependendo do ritmo de transformação da paisagem (Ibidem).

Ainda segundo o autor, estas transformações se dão devido às mudanças de funcionalidade dos subespaços, em razão da divisão territorial do trabalho, ou ainda, dão-se estruturalmente, pela alteração das formas, ou a soma das duas causas.

No entanto, o centro tradicional, por expressar uma centralidade maior em relação às demais porções do espaço urbano, concentra grande número de indivíduos que habitam, trabalham, consomem ou somente transitam pelo local. Dessa forma, a paisagem do centro é heterogênea, ainda que não haja equilíbrio no poder de produção do espaço entre os indivíduos.

Neste sentido, a preservação do centro tradicional se impõe pela salvaguarda de antigas formas de organização do espaço e da paisagem e, consequentemente, da memória do passado, que no presente constitui-se em bens culturais.

Ao contrário da paisagem, o espaço contém o movimento da sociedade, mas os dois compõem um par dialético, o que demanda esforços para reconhecer suas diferenças (SANTOS, 1988; 2008). Tanto o espaço, quanto a paisagem são a sociedade. Mas se a paisagem existe através de suas formas, o espaço é a função atual que as formas exibem. "O espaço constitui a matriz sobre a qual as novas ações substituem as ações passadas. É ele, portanto, presente, porque passado e futuro." (Ibidem, 2008, p. 104).

Para Milton Santos (2008), o espaço se constitui num híbrido entre sistemas de objetos e sistemas de ações. É esta relação dialética entre espaço e sociedade que dá vida ao espaço, que não possui movimento próprio. Este espaço ao receber a ação humana, a recebe enquanto espaço-conteúdo, realidade social. 
Revista Nacional de

Gerenciamento de Cidades

Estudiosos como Durkheim consideraram o consumo como um setor anômico, por não ser construído coletivamente, e assim expressaria a liberdade individual. No entanto, para Baudrillard (2010), o consumo se configura como sistema de valores e instrumento de integração social. A sociedade de consumo se notabiliza, portanto, pelo modo específico de socialização, baseado no consumo de mercadorias, espaços e serviços. Ainda segundo Braudrillard:

Toda ideologia do consumo pretende levar-nos a crer que entremos numa era nova e que uma Revolução Humana decisiva separa a Idade dolorosa e heroica da Produção da Idade eufórica do Consumo, em cujo seio se faz justiça ao Homem e aos seus desejos (Ibidem, p. 97).

Baudrillard procura contribuir com o desenvolvimento de um contexto onde 0 consumo invade a sociedade no sentido de integração dos fenômenos e os elementos que o cerca. Neste processo, destaca que

à nossa volta, existe hoje uma espécie de evidências fantásticas do consumo e da abundância, criada pela manipulação dos objectos, dos serviços, dos bens materiais, originando como uma categoria de mutação fundamental na ecologia da espécie humana (Ibidem, p. 13).

$\mathrm{Na}$ busca por desenvolver uma proposta de intervenção para a valorização do centro da cidade em relação ao espaço de consumo mais moderno, um shopping center, pretende-se trabalhar com o consumo alicerçado sobre as novas relações estabelecidas entre os objetos e os sujeitos.

É importante ressaltar o debate ainda sobre as vitrines:

A vitrina, todas as vitrinas, que constituem, com a publicidade, o foco de convencção das nossas práticas urbana, consumidoras, são por excelência o lugar da <operação- consenso>, da comunicação e da permuta de valores através da qual toda uma sociedade se torna homogênea por meio de incessante aculturação quotidiana à lógica, silenciosa e espetacular, da moda (lbidem, p. 223).

Em contraposição a esse espaço, propõem-se identificar possibilidade de considerar o "espaço público" do centro com uma esfera que abarca um novo consumo, logo a sua valorização mediante aos olhares, por apresentarem o espaço como uma característica simples e comum, mediante ao seu consumo do local. 


\section{Revista Nacional de}

Gerenciamento de Cidades

\section{CONCLUSÃO}

Nas últimas décadas o consumo tem alcançado níveis cada vez mais altos e uma importância sem precedentes no cotidiano de pessoas de diferentes segmentos socioeconômicos, sendo o shopping center um lugar privilegiado para o consumo por apresentar uma paisagem de modernidade, segurança e conforto, pois além das mercadorias, consome-se também o espaço.

O shopping se apresenta como um espaço intencionalmente construído para o consumo, sendo sua paisagem idealizada para este fim. Porém, esse espaço de consumo foi premeditado para uma sociabilidade das classes mais abastadas em oposição ao centro de consumo tradicional (calçadão), caracterizado pelas aglomerações de pessoas de diferentes classes sociais.

Embora, o centro possa ser caracterizado como o lugar mais dinâmico da cidade, ao atrair grandes fluxos de pessoas, mercadorias e informações, potencializada pelo acúmulo de atividades diversas, comerciais, financeiras, políticas, religiosas, de lazer e de cultura; além de possuir importância simbólica, por concentrar grande parte do patrimônio histórico-cultural da sociedade, seu papel enquanto espaço de consumo tem sido relativizado frente a emergência de novas áreas centrais.

De acordo com Mancini (2008), os espaços públicos refletem as relações nas sociedades de diversas épocas e que irão deles desfrutar. Sendo assim, devese levar em consideração a importância de realizar reformas e manutenções dos espaços públicos pelas diferentes gerações, a fim de implementar novas formas de uso que respeite o local como espaço de todos.

Não propomos, com isso, intervenções que proporcionem crescentes semelhanças entre o centro da cidade e o shopping center, mas tentativas de atração de citadinos a partir de características próprias do centro, como a 


\section{Revista Nacional de}

Gerenciamento de Cidades

possibilidade do encontro entre diversas classes sociais e de proteção do patrimônio arquitetônico, ligado à memória da cidade.

De acordo com estudos recentes (Ibidem), através de questionários aplicados, verificou-se que a população almeja melhorias nas Praças. Dentre os anseios, foram citados a segurança, banheiros e bebedouros e também foi requerido atividades culturais, como shows, teatros e, para idosos, retretas e a volta dos eventos referente ao coreto.

É importante salientar que tal proposta de intervenção não visa atender necessidades de alguns segmentos da sociedade, mas sim é direcionada à proteção da identidade histórica e cultural e fortalecer a noção de coletividade nos espaços públicos, além disso, busca-se recuperar no calçadão as práticas de convívio social.

\section{REFERÊNCIAS BIBLIOGRÁFICAS}

ABREU, D. S. Formação histórica de uma cidade pioneira paulista: Presidente Prudente. Presidente Prudente: Faculdade de Filosofia, Ciências e Letras, 1972.

AGOSTINHO, M. V. V. de. Reabilitação da área central de Presidente Prudente:

interligando a praça da bandeira ao seu entorno. Presidente Prudente, 2009. 94f. Monografia (Bacharel em Arquitetura e Urbanismo) - Faculdade de Ciência e Tecnologia, Universidade Estadual Paulista.

BAUDRILLARD, J. A sociedade de consumo. Lisboa: Edições 70, 2010.

CARLOS, Ana Fani Alessandri. A (re) produção do espaço urbano. São Paulo: Edusp, 1994. 2001.

Espaço-Tempo na Metrópole: a fragmentação na vida cotidiana. São Paulo: Contexto,

CLAVAL, P. A geografia cultural. Florianópolis: UFSC, 1999.

"A volta do cultural” na Geografia. Mercator. Revista de Geografia da UFC, Fortaleza, ano 1, número 01, 2002.

CORRÊA, R. L., A dimensão cultural do espaço: alguns temas. Espaço Cultural. Ano I, outubro de 1995.

PREFEITURA DE NITERÓl. Diagnóstico do Programa da Sub-Região Centro. Programa Viva Centro Diagnóstico e Propostas para o Projeto de Reabilitação do Centro de Niterói. Agosto, 2006. 
